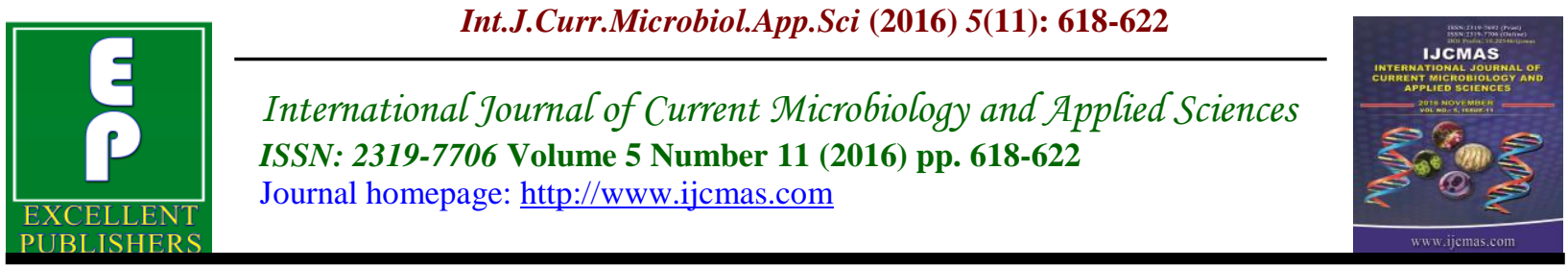

Original Research Article

http://dx.doi.org/10.20546/ijcmas.2016.511.072

\title{
Comparing Quality of Life (QoL) during Pregnancy among Pregnant Women Referring to Public or Private Hospitals
}

\author{
Samaneh Mousavi ${ }^{1}$, Abbas Yazdanpanah ${ }^{1 *}$ and Irvan Massoudi Asl ${ }^{2}$ \\ ${ }^{1}$ Department of Healthcare management, Marvdasht Branch, Islamic Azad University, \\ Marvdasht, Iran \\ ${ }^{2}$ Health Service Management Department, School of Medical School of Medical Sciences, \\ Islamic Azad University, Science and Research Branch, Teheran, Iran \\ *Corresponding author
}

Keywords

Pregnancy,

Quality of life

(QoL),

Education level, Age.

Article Info

Accepted:

26 October 2016

Available Online:

10 November 2016

\section{A B S T R A C T}

Quality of life (QoL) includes different dimensions of physical, mental, and socioeconomic quality and health of individuals. These dimensions can be measured during pregnancy. The present study is aimed to compare the quality of life during pregnancy among pregnant women referring to public and private hospitals in Shiraz, Iran. The present study is a cross-sectional descriptive-analytical research conducted in 6selected hospitals in city of Shiraz. The samples included pregnant women referring for prenatal cares and inclusion criteria. Among these samples, 253 were from public hospitals and 253 from private hospitals (505 in total). Sampling was performed using convenient purposive sampling method. Then, the participants' verbal consent was obtained. Data was collected using SF-36 QoL questionnaire and analyzed in SPSS software. There was a significant relationship between education and age of the participants and their quality of life in both groups $(\mathrm{P}<0.001)$. Further, QOL mean score of the women referring to the public hospitals was higher than that of those referring to the private hospitals $(\mathrm{p}<0.001)$. Results of this study indicated that the variables of education and age at the time of pregnancy were the main variables affecting QoL during pregnancy.

\section{Introduction}

Pregnancy is often considered as a stressful period which is associated with physiological and psychological changes for women. These changes can reduce QoL in a large number of women (Makvandi and Kermani, 2012). In addition to causing adverse consequences such as premature delivery and low birth weight, poor health status in pregnant women might reduce the maternal-fetus attachment (Kerdar, 2014). Researchers have shown that physical function of the body, as one of the QoL dimensions, is reduced during pregnancy (Otchet et al., 1998). Measuring QoL among pregnant women is important in planning for maternal and neonatal cares (Otchet et al., 1998). QoL can be assessed at all stages of 
life including prenatal and postnatal periods (Pesavento et al., 2005). Numerous variations occur during and after pregnancy in different of mental, social, and physical health dimensions and, ultimately, in QoL among women (Rayan et al., 1999). Fatigue, nausea, vomiting, headache, anorexia, heartburn, hemorrhoid, and shortness of breath are some of the symptoms with which natural pregnant women are faced. These factor scan change women's ability to carry out their ordinary roles in life and influence their QoL (Gordon, 2007). Regarding the sensitivity of the issue of reproductive health and promotion of QoL in pregnant women, this study is aimed to compare QoL during pregnancy among the pregnant women referring to public and private hospitals in city of Shiraz.

\section{Methodology}

The present study is a cross-sectional descriptive-analytical research which was conducted in2016 in 6selected hospitals in city of Shiraz, Iran, including 3 public and 3 private hospitals. The samples included 505 pregnant women referring to the hospitals for prenatal cares and had the inclusion criteria. Sampling was performed using convenient purposive sampling and, then, the verbal consent of the participants was obtained. The inclusion criteria included tendency to participate in the study, gestational age of above 20 weeks, having live fetus, lack of special disease in mother, and lack of gestational problem (such as preeclampsia, diabetes, bleeding, hydramnios, etc.); further, the exclusion criteria included incomplete questionnaires.

SF-36 questionnaire was used to assess QoL. This self-reporting questionnaire which is mainly used to investigate QoL and health consists of 36 statements and assesses 8 domains, including physical functioning, social role functioning, physical role functioning, emotional role functioning, mental health, vitality, bodily pain, and general health; furthermore, it provides two general measurements of functioning: the overall physical component score (PCS), which measures the physical dimension of health, and the overall mental component score (MCS), which assesses the psychosocial dimension of health. Participants's cores in each of these domains ranges between 0 and100, and higher scores indicate better QoL. Validity and reliability of the questionnaire in the Iranian population were approved by Montazeri et al., (2005). After completing the questionnaires, descriptive statistics and frequency were used. Data analysis was performed in SPSS software.

\section{Results and Discussion}

For the demographic characteristics of the women referring to public hospitals, the highest and lowest age frequencies were less than 30 years $(50.2 \%)$ and above 40 years $(5.7 \%)$, respectively. In terms of family headship status, most of the participants $(95.5 \%)$ were under guardianship. In terms of housing status, the majority of them were living in cities $(72.9 \%)$; moreover, in terms of employment status, the majority of them were housewife (55.5). Further, most of the participants in this group had high school diplomas (32.4\%) (Table-1).As for the demographic characteristics of the women referring to private hospitals, the highest and lowest frequencies were related to the ages ranging from 31 to 40 years old $(50.2 \%)$ and above 40 years old (7.2\%), respectively. Regarding family headship status, most of the participants were under guardianship $(0.78 \%)$. In terms of housing status, the majority of the participants were living in cities $(84.3 \%)$; further, most of the women were employed (48.8\%). Moreover, in terms of education, the highest frequency was related to associate degrees and higher 
$(66.9 \%)$ (Table-2).

Results showed a significant difference between the QoL scores of the women referring to the private hospitals and those referring to the public hospitals; thus, the mean score of QoL of the women referring to the public hospitals was higher than that of the women referring to the private hospitals $(\mathrm{p}<0.001)($ Table-3).

Although pregnancy takes its natural course during women's reproduction period, it is often associated with fears and concerns, which can cause anxiety and stress as important factors affecting the QoL in pregnant women (Abaszadeh et al., 2008).
In the investigation by Bodecs et al., (2009), the prevalence of the prenatal anxiety and depression among the study population was 17.9\%; however, it was estimated higher for unemployed women with low-income and less than 18 years of age (Bodecs et al., 2009).

The present study was aimed to compare QoL during pregnancy among the pregnant women referring to public and private hospitals in Shiraz, Iran. The obtained results demonstrated that the mean score of QoL of women referring to the public hospitals was higher than that of those referring to the private hospitals $(\mathrm{p}<0.001)$.

Table.1 Demographic characteristics of the women referring to Public hospitals

\begin{tabular}{|c|c|c|c|}
\hline \multicolumn{2}{|c|}{ Demographic characteristics } & Frequency & Number \\
\hline \multirow{3}{*}{$\begin{array}{l}\text { Age } \\
\text { (year) }\end{array}$} & $<30$ & 50.2 & 124 \\
\hline & $31-40$ & 44.1 & 109 \\
\hline & $>40$ & 5.7 & 14 \\
\hline \multirow[t]{3}{*}{ Family headship status } & Households & 2.8 & 7 \\
\hline & Under guardianship & 95.5 & 236 \\
\hline & Self management & 1.6 & 4 \\
\hline \multirow[t]{2}{*}{ Housing status } & City & 72.9 & 180 \\
\hline & Village & 25.1 & 61 \\
\hline \multirow[t]{4}{*}{ Employment status } & Employed & 36.4 & 90 \\
\hline & Unemployed & 4.5 & 11 \\
\hline & Student & 2.8 & 7 \\
\hline & Housewife & 55.5 & 137 \\
\hline \multirow[t]{4}{*}{ Education } & Primary & 7.7 & 19 \\
\hline & Guidance level & 29.8 & 71 \\
\hline & High school diploma & 32.4 & 80 \\
\hline & Associate Degree and more & $27 / 9$ & 66 \\
\hline
\end{tabular}


Table.2 Demographic characteristics of the women referring to Private hospitals

\begin{tabular}{|c|c|c|c|}
\hline \multirow{2}{*}{ Demographic characteristics } & Frequency & Number \\
\hline \multirow{3}{*}{$\begin{array}{c}\text { Age } \\
\text { (year) }\end{array}$} & $<30$ & 7.42 & 213 \\
\cline { 2 - 4 } & $31-40$ & 1.50 & 250 \\
\cline { 2 - 4 } & $>40$ & 7.2 & 36 \\
\hline \multirow{3}{*}{ Family headship status } & Households & 3.17 & 44 \\
\cline { 2 - 4 } & Under guardianship & 78.0 & 198 \\
\cline { 2 - 4 } & Self management & 9.3 & 10 \\
\hline \multirow{3}{*}{ Housing status } & City & 3.84 & 214 \\
\cline { 2 - 4 } Employment status & Village & 13.0 & 33 \\
\cline { 2 - 4 } & Employed & 8.48 & 124 \\
\cline { 2 - 4 } & Unemployed & 1.16 & 41 \\
\cline { 2 - 4 } & Student & 2.1 & 3 \\
\hline \multirow{7}{*}{ Education } & Housewife & 3.30 & 77 \\
\cline { 2 - 4 } & Primary & 08.0 & 2 \\
\cline { 2 - 4 } & Guidance level & 11.0 & 28 \\
\cline { 2 - 4 } & High school diploma & 37.19 & 49 \\
\cline { 2 - 4 } & Associate Degree and more & 9.66 & 170 \\
\hline
\end{tabular}

Table.3 Comparison the quality of life score between the women referring to the private and public hospitals

\begin{tabular}{|c|c|c|c|c|c|}
\hline \multicolumn{2}{|c|}{ Public hospitals } & \multicolumn{2}{|c|}{ Private hospitals } & t & P -value \\
\hline $\mathrm{N}$ & Mean \pm SD & $\mathrm{N}$ & Mean \pm SD & \multirow{2}{*}{3.68} & \multirow{2}{*}{0.001} \\
\hline 240 & $8.5764 \pm .99$ & 242 & $97.09 \pm 6.5$ & & \\
\hline
\end{tabular}

In another study by Zahedi and Deris (2012) on QoL among the pregnant women in city of Farokhshahr, the meanscore of QoL in different dimensions of health status was moderate and higher, which is consistent with the results of the present study; furthermore, there was an inverse and significant relationship between age and all the dimensions of QoL $(\mathrm{p}<0.05)$.

A cross-sectional study was conducted by Abbaszadeh et al., (2008) on 600 pregnant women in order to investigate their QoL.
Findings of this research showed a statistically significant relationship between age, gestational age, number of pregnancies, and level of education on the one hand and the mean scores of QoL in some dimensions on the other hand, which is almost consistent with the results of the present study. Effect of education on the QoL during the period of non-pregnancy has been proved, and even many studies have represented that this effect is more than the effect of age. This finding indicates that education, as an advantage, is effective in the enjoyment of a 
healthy lifestyle during pregnancy, which would lead to sense of better health and satisfaction during pregnancy period. The study conducted by Hueston et al., to determine the variables affecting women's prenatal and postnatal health showed a significant relationship between the financial status insufficient for providing food and housing and the pre, peri, and postnatal poor health status (Hueston, 2004).

In conclusion, the significant relationship of education and age with QoL among the pregnant women indicated that education, as an advantage, is effective in the enjoyment of a healthy lifestyle during pregnancy, which leads to sense of better health and satisfaction during pregnancy. Age of a pregnant woman is considered as one of the most influential factors of QoL. Therefore, family health authorities are recommended to provide necessary educational programs for training and guiding the pregnant women in terms of appropriate age of pregnancy.

\section{References}

Abaszadeh, F., Bagher, A., Mehran, N. 2007. Quality of life in pregnant women.

Gordon, M.C. 2007. Maternal physiology. In: Gabbe SG, Niebly JR, Simpson SG, editors. Obstetrics: normal and problem pregnancies. 5th ed. Philadelphia: Elsevier.
Hueston, W., Kasik-miller, S. 1998. Changes in functional health status during normal pregnancy. The $J$. Family Practice, 46: 209-12(13-22).

Kerdar, R. 2014. Quality of Women Diabetic.

Makvandi, S., Kermani, A.E. 2012. Quality of life of pregnant women referred to health centers in Izeh (2010). $J$. Kermanshah University of Med. Sci., (J. Kermanshah Univ. Med. Sci)., 16(1): 37-42.

Montazeri A., Gashtasebi, A., Vahdaninia, M. 2005. translating 'determining the raliability and validity of persian format of SF-36 questionnaire. Payesh J., 5(1): 49-56.

Otchet, F., Carey , S., Adam, L. 1999. General health and psychological symptom status in pregnancy and the purperium: what is normal? Obstetrics and Gynecol., 94: 935-41.

Pesavento, F., Marconcini, E., Drago, D. 2005. Quality of life and depression in normal and in high-risk pregnancy،analysis of a sample of 100 women. Minerva Gynecol., 57(4): 451-60.

Ryan, K.J., Berkwitz, R., Barbien, R. 1999. If A.D. Kistner's Gynecology \& women's health. 7thed. Boston: Mosby.

Zahedi, M., Deris, F. 1391. Quality of life in pregnant women in the city of farokhshahr.

\section{How to cite this article:}

Samaneh Mousavi, Abbas Yazdanpanah and Irvan Massoudi Asl. 2016. Comparing Quality of Life (QoL) during Pregnancy among Pregnant Women Referring to Public or Private Hospitals. Int.J.Curr.Microbiol.App.Sci. 5(11): 618-622. doi: http://dx.doi.org/10.20546/ijcmas.2016.511.072 